\title{
Assessing Reliability and Credibility for Online Engineering Resources
}

\author{
Beth E. Kolko, Linda Whang \\ University of Washington
}

\section{Introduction}

The easy availability of material on the Web means that students are increasingly turning to electronic resources for research purposes. While many resources that are accessible electronically parallel familiar print resources and are, often, simply online versions of familiar databases and catalogs, there exists a large quantity of information that rests outside familiar frameworks for published research. The authors of this paper work as a professor and an engineering librarian respectively, and in our work we have watched as both undergraduate and graduate students struggle to adapt to an increasingly electronic environment for research. As students come to rely on the Internet to access resources, they are often not critical consumers of information, and they often do not differentiate among resources gained via universitysubscribed databases versus resources that reside outside such databases and are part of the 'open' Web.

This paper examines strategies for instructing students about the variety of resources available for online research and the necessity of differentiating among database-related resources and independently posted research. In addition, we focus on the crucial issues of reliability and credibility with respect to online resources. Traditional ways of assessing these factors are not always relevant in an online environment, and it is imperative that we as educators develop curricula that address the procedures and goals of responsible secondary research. For example, reading research results published in a journal that is part of the ACM Digital Library requires a different critical reading strategy than reading the pages of research groups at the MIT Media Lab. This is different still from using unpublished papers available on the Web as a component of a research paper. Teachers are increasingly developing guidelines for their students' use when it comes to learning to use such a wide variety of electronic resources responsibly and effectively, and this paper is an attempt to bring together many of those efforts, compiling different strategies and providing a framework for extending and refining them. Ultimately, of course, our goal is to discuss the utility of proposing discipline-specific criteria for dealing with these general issues and laying out some general strategies for engineering educators.

\section{The Internet as a Research Resource for Students}

That the World Wide Web has become integrated into higher education is clear. Both students and teachers continue to find novel uses for information technology both inside and outside the classroom. And despite worries of plagiarism and reinforcing sloppy writing habits, the Internet 
has brought some strong innovations to education and research. For example, as Kenneth Lancaster, et al. argue, students who do research on the Internet show increased interest and involvement in their studies. Additionally, they are "less passive about how they pursue knowledge," and when the Internet is involved, students appreciate being "forced to seek out information for topic discussions and research papers." [10] While the general shift in student attitudes is positive, and dovetails with many broad goals of curriculum reform by integrating active learning principles, the shape of how learning occurs is not separable from the content of what gets learned. Indeed, as Lancaster, et al. point out, "[m]aterials and information from the Internet...may also be undisciplined, often misleading and inaccurate, and potentially counterproductive for both faculty and student research." They also mention that students, because they often lack a firm foundation in the research literature of their field, are "particularly vulnerable to unwise source selection from the Internet." [10] Teaching students effective research habits is hardly a new requirement in the university. Whether they end up relying on marginal journals, one or two sources, or out-of-date resources, student researchers have always faced challenges as they become accustomed to the culture of research. Discerning the general category of journals in a field from the top journal in a field may come naturally to longtime practitioners, but how to make such distinctions is not immediately apparent to students. The use of the Internet as a major component of research-based assignments has complicated a process for which teachers and librarians had developed particular curricular strategies.

Philip M. Davis and Suzanne A. Cohen have compared student papers written in 1996 and 1999 and have documented that student use of Internet sites has increased in this time. In addition, they noted a "significant decline in the mean use of scholarly materials" (scholarly materials being cited books and journal articles). [5] Although this study reflects only one undergraduate class and a small sample size, anecdotal evidence corroborates these observations in the work of Engineering students as well. [3] Clearly, it is time to develop specific curricular strategies to deal with changes in teaching and learning practices, and discussing such changes as a field can allow us to establish expectations and standards.

\section{Evaluating Electronic Information Sources}

Echoed throughout a wide variety of literature is a call for educators to teach students to critically evaluate information they find on the Internet. For example, as Kristin Kubly argues, "[i]t is important that educators are able to guide students in using the World Wide Web appropriately by teaching them to evaluate internet resources using criteria designed to weed out the authoritative sources." [9] Indeed, for a productive pedagogical strategy to emerge, instructors must be able to model effective research strategies for students. Such strategies include not just finding sources on a particular topic, but also being able to assess the validity of sources. While this general approach has always been key in research-based activities, the Web complicates the processes by which sources are evaluated. And it becomes doubly important for instructors to be able to provide guidelines for students that enable them to make informed choices about which Web resources to draw upon when doing research. When Kubly goes on to say that "educators must be familiar with the kind of sources out on the Web and themselves be able to identify which are legitimate so that they may guide students in using the Web for research," [9] she is pinpointing instructors' responsibility with respect to Internet-based research. 


\section{Discipline-specific Strategies For Evaluating Websites: Establishing Criteria}

There have been several exploratory and research-based studies that attempt to articulate criteria for evaluating electronic resources. The evaluation criteria that are mentioned most often with respect to websites are accuracy, authority, objectivity, currency, and coverage. [15] Print-based evaluation criteria are often invoked as one method for managing the challenge of unverified Web resources. These criteria include looking at authorship, the publishing body, point of view or bias, referral to other sources, verifiability, and currency. [1] However, it can be difficult to deploy such criteria with respect to websites, and thus the teaching of information literacy skills is paramount. [12] Such skills can include elements of an evaluation worksheet developed by Michael O'Sullivan and Thomas Scott which asks students to look at several factors related to specific criteria. These include questioning whether links are accurate, sources are cited, the author has listed qualifications, and information contains a bias as well as whether information on the site is updated regularly. [12]

In the discipline of English, several instructors have generated strategies for using Web resources, and their innovations can form the basis of engineering-specific information literacy skills. For example, Catherine B. Elliott has found the following three strategies crucial to helping students use Web resources effectively. She advocates teaching students key word skills, how to use databases that are available at the institution, and having teachers pre-select groups of websites. She calls these pre-selected sites "Pathfinders" and while creating such a list can be a lengthy process for the first time a class is taught, it does seem like an effective long-term strategy for allowing students to use the Internet as a research resource with confidence. Additionally, creating such "pathfinders" can model for students what a reliable Web resource might look like, which in turn can help them to make accurate judgments when they find additional resources on their own. [6]

The research of Vicki Tolar Burton and Scott A. Chadwick has demonstrated that students do use evaluation criteria when they look at Web sources, and that they tend to transfer what they have learned regarding evaluation of print resources to Internet-based information. On the other hand, as they demonstrate, the most important criteria for students seems to be the level of access. That is, easily accessible sources are often leveraged to form the crux of student research. However, their subjects also reported valuing recent information and reputation of the publishing source. [2] We claim that what is crucial at this juncture is developing criteria specifically designed for engineering educators and students. While educators across the university are experiencing similar problems, the exigencies and demands of engineering education demand a disciplinespecific solution. This is especially important in light of Susan Davis Herring's research on faculty acceptance of the World Wide Web in student research, which found that among the disciplines, "engineering/computer science faculty were least likely to require students to use other sources in conjunction with the Web." [8]

\section{Conclusion: Strategies for Engineering Educators}

Primary among our suggestions for engineering is to make use of Internet portals that operate as screening mechanisms on the World Wide Web. For example, instructors can explore the 
possibility of using engineering portals, such as those described in Ronald H. Rockland's "Reducing the Information Overload: A Method on Helping Students Research Engineering Topics Using the Internet." In his article, Rockland describes search engines, metasearch engines, general technical pages, and discipline-specific portals that can help direct students to reliable sources for their research endeavors. [14] While Rockland's information is valuable, and the process he outlines productive, at times instructors will want to encourage students to look outside boundaried sites for relevant information. And, of course, students often develop their own Web searching strategies that do not necessarily rely on portals and other carefully constructed sites. Instructors, then, are left with the question of how to best direct students to appropriate resources even when searches are conducted outside the boundaries of the electronic version of refereed journals. Since engineering education poses discipline-specific challenges and incorporates discipline-specific expectations, we believe it is important to develop guidelines that respond to the needs of engineering educators and students, even under the unrestricted conditions of the open Web. Following are some specific curricular suggestions we have developed in order to address this need.

1. Require students to find, use, and cite journal or conference literature in their research projects or papers. As Davis and Cohen point out, "students are very literal with the requirements of their term-paper assignment." They argue that "professors ought to be more prescriptive with the type of literature that they would like to see consulted." [5] In a followup study, Davis also recommends that instructors provide "guidelines, examples, [and] minimum research standards in class assignments." [4] That is, verbally communicating this information is not adequate to change students' tendency to rely on Internet resources in favor of research literature. Since most students have no idea where to begin to find this type of information, it would be helpful to enlist the aid of a librarian who can provide instruction on which databases are available for their research and how to search them. In addition, librarians can explain the differences between subscription databases available. For example, a student may do a search in IEEE Xplore and find 25 articles on her topic and think that she has done a "comprehensive" search, however, she is not aware that this database only gives her access to a portion of the journal literature in the field of electrical engineering, and that an index such as INSPEC would allow her to access many more journals in the field beyond those published by IEEE and IEE.

2. Provide students with a list of specific websites that do contain authoritative information in the field and require that they limit their Web sources to these sites. This echoes Elliott's strategy of creating a "Pathfinder," but it also allows educators to emphasize the sources that are most relevant and most reliable for their field. Jill H. Powell has reviewed a number of Engineering Virtual Libraries available on the Internet [13], and Roddy Macleod lists several Engineering Portals which provide "one-stop technical information" [11]; these may be used by students as starting points to find more authoritative engineering information on the Internet.

3. Assume that your students will find other websites on their own, either through Web searches, links from other Web pages, or friends' suggestions, and provide them with a list of criteria that can be used to evaluate the quality of information found. Evaluation criteria as applied to Engineering resources on the Internet include: 
a. Accuracy: is the source of information clearly listed so that it can be verified in another source; is the information free of grammatical, spelling, and typographical errors; is it clear who has responsibility for the accuracy of the content of the material; if there are charts and/or graphs containing data, are they clearly labeled and easy to read? [14] Accuracy of technical data such as the load-bearing capacity of a steel beam or the resiliency of an O-ring is vitally important to successful Engineering design and human safety. Students should be critical of technical information found on the Internet and be aware of reference resources, such as handbooks, that can be used to verify any data found on the Internet.

b. Authority: is the author's name marked; can the author be contacted; are the author's credentials stated; is the institution with which the author is affiliated indicated; based upon the author's credentials, is he/she reliable? [7] Students should be aware of the many different organizations that provide engineering-related information on the Internet (e.g. ASCE, ASME, IEEE, IEE, NASA, NIST, etc.) and be able to distinguish between professional organizations and other sources of information such as businesses and manufacturers of engineering products and materials.

c. Objectivity: is the information provided as a public service or as a form of advertising? Students should be able to critically evaluate the source for objectivity. For example, information on the safety of a plastic used in food containers may be more objective coming from an organization such as the FDA than a plastics manufacturer.

d. Currency: is the publication date given; is the information updated regularly? Currency is especially important in engineering when it comes to technical information such as standards. Students should be aware of Standards databases such as ILI Standards Infoweb Search (http://www.ili-info.com) or Global Engineering (http://www.global.ihs.com), which they can search for up-to-date standards information.

e. Coverage: is there an indication that the page has been completed and is not still under construction; is there a print equivalent to the Web page; is there a clear indication of whether the entire work is available on the Web or only parts of it; if the material is from a work which is out of copyright, has there been an effort to update the information to make it more current? [15]

4. Give students an overview of the different kinds of information available on the Internet. With the increasing number of journals available online, and as access to subscription-based research databases such as Compendex, INSPEC, IEEE Xplore, the ACM Digital Library, Lexis-Nexis, etc. has become transparent, it is becoming more and more difficult for students to determine which information sources are authoritative and reliable, and which ones come from the "open" Web. Providing an overview of these different types of information (open, undisciplined, unverifiable information versus restricted, subscription index databases and online journals and reference books) with examples of each, and allowing students to 
compare the different types, might help them determine which type(s) of information they encounter as they do their own research.

5. Have students verify technical information found on the Web in a print resource, such as the CRC Handbook of Chemistry and Physics. Many industrial sites will post technical data, such as specific heat capacity of metals, on their websites, but students must be wary of this data unless they can verify its accuracy in a print resource. Establishing the link between online and offline information can allow students to leverage any research-related strategies for print resources that they may have learned previously. By demonstrating to students that electronic resources are part of a continuum of research information, we can help them situate what they find on the Web as part of a larger conversation of scholars.

6. Explain the differences among print-based resources like popular magazines, research journals, and trade journals. Each is written for a very different audience, with different controls on accuracy and verifiability. Students already have some media literacy skills, and part of our challenge is to tap into those skills and demonstrate to students that the work they do everyday as they read a newspaper or magazine is relevant to thinking about research as well. Articulating the differences among such print-based resources and showing students how to critically evaluate these types of information sources can provide a basis for them to think about source evaluation in the broadest definition.

It is our hope that these suggestions will help your students learn how to critically evaluate the engineering information they find on the Internet and become more informed and aware consumers of technical information.

Bibliography

1. Brandt, D. Scott. "Evaluating Information on the Internet," Computers in Libraries 16 (1996): 44-46.

2. Burton, Vicki Tolar and Scott A. Chadwick. "Investigating the Practices of Student Researchers: Patterns of Use and Criteria for Use of Internet and Library Sources," Computers and Composition 17 (2000): 309-28.

3. Christie, Rich. "Library resource assignments." E-mail to Linda Whang. 2 Jan. 2002.

4. Davis, Philip M. "The Effect of the Web on Undergraduate Citation Behavior: A 2000 Update," College \& Research Libraries 63 (2002): 53-60.

5. Davis, Philip M. and Suzanne A. Cohen. "The Effect of the Web on Undergraduate Citation Behavior 19961999," Journal of the American Society for Information Science and Technology 52 (2001): 309-314.

6. Elliott, Catherine B. "Helping Students Weave Their Way through the World Wide Web," English Journal 90 (2000): 87-92.

7. German, Aimee Lynn. Science and Information Literacy on the Internet: Using the Standards Created by the Association of College and Research Libraries and Project 2061 To Create a Science Webpage Evaluation Tool. Master's Research Paper. Kent, Ohio: Kent State University, 2000. 
8. Herring, Susan Davis. "Faculty Acceptance of the World Wide Web for Student Research," College \& Research Libraries 62 (2001): 251-258.

9. Kubly, Kristin. "Guiding Students in Using the World Wide Web for Research." Mid-South Instructional Technology Conference, Murfreesboro, TN, April 6-8, 1997. 15 January 2002.

<http://www.mtsu.edu/ itconf/proceed97/kubly.html>.

10. Lancaster, Kenneth, et al. "Internet Research Applications in Health and Human Services Degree Programs: Promises and Problems." Mid-South Instructional Technology Conference, Murfreesboro, TN, April 5-7, 1998. 15 January 2002. <http://www.mtsu.edu/ itconf/proceed98/klancaster.html>.

11. Macleod, Roddy. "Panorama of Engineering Portals," Free Pint 66 (2000). 14 March 2002. $<$ http://www.freepint.com/issues/060700.htm\#tips>.

12. O’Sullivan, Michael and Thomas Scott. "Teaching Internet Information Literacy: A Critical Evaluation," MultiMedia Schools 7 (2000): 40-44.

13. Powell, Jill H. "Virtual Engineering Libraries," Science and Technology Libraries 19 (2001): 105-128.

14. Rockland, Ronald H. "Reducing the Information Overload: A Method on Helping Students Research Engineering Topics using the Internet," IEEE Transactions on Education 43 (2000): 420-425.

15. Tate, Marsha Ann and Jan Alexander. Checklist for an Informational Web Page. 14 March 2002 <http://www2.widener.edu/Wolfgram-Memorial-Library/webevaluation/inform.htm>.

BETH E. KOLKO is an Associate Professor in the Department of Technical Communication at the University of Washington. She holds a BA from Oberlin College and an MA and PhD from the University of Texas at Austin. Her research specialties are computer-mediated communication, virtual environments, and international issues related to information and communication technologies. She has been teaching with computers since 1991, with both English and Engineering students.

LINDA WHANG is the Instructional Services Librarian in the Engineering Library at the University of Washington. Prior to that, she served as Engineering Librarian at the State University of New York at Binghamton and as a health sciences librarian at the University of Michigan. Ms. Whang has a BS in Biological Sciences from Cornell University and an MLS from the State University of New York at Buffalo. 